\title{
The impact of prenatal maternal risk, fearless temperament and early parenting on adolescent callous-unemotional traits: a 14-year longitudinal investigation
}

\author{
Edward D. Barker, ${ }^{1}$ Bonamy R. Oliver, ${ }^{2}$ Essi Viding, ${ }^{3}$ Randall T. Salekin, ${ }^{4}$ and \\ Barbara Maughan ${ }^{2}$ \\ ${ }^{1}$ Psychological Science, Birkbeck, UK; ${ }^{2}$ MRC Social, Genetic and Developmental Psychiatry Centre, King's College \\ London, Institute of Psychiatry, London, UK; ${ }^{3}$ University College London, Division of Psychology and Language \\ Sciences, London, UK; ${ }^{4}$ University of Alabama, USA
}

\begin{abstract}
Objective: Proposals have been submitted to the DSM-V for the addition of a callous-unemotional (CU) specifier for conduct problem $(\mathrm{CP})$ youth $(\mathrm{CP} / \mathrm{CU})$. While the addition of such a diagnostic category may aid in the identification of homogeneous CP subtypes, evidence on risks for the development of $\mathrm{CP} / \mathrm{CU}$ remains limited. The present study sought to examine the extent to which $\mathrm{CP} / \mathrm{CU}$ in early adolescence could be differentiated by family- and child-based risks from pregnancy to age 4 years. Method: Using data from approximately 7,000 mothers and their offspring (51\% male) participating in the Avon Longitudinal Study of Parents and Children, the authors examined maternal prenatal risks (psychopathology, criminality, substance use), child's fearless temperament (age 2 years) and harsh and warm parenting (age 4 years) as predictors of $\mathrm{CP}$ and $\mathrm{CU}$ at age 13; then used follow-back analyses to explore pre- and early post-natal risks in more detail. Results: Maternal prenatal risks increased fearless temperament and $\mathrm{CP}$ and $\mathrm{CU}$. Fearless temperament was also prospectively associated with higher levels of early adolescent $\mathrm{CP}$ and $\mathrm{CU}$, above and beyond parenting and prenatal maternal risks. Followback analyses showed fearless temperament in boys manifested as lower response to punishment cues, while for girls this temperament was indexed by boldness toward novel situations and strangers, particularly for $\mathrm{CP} / \mathrm{CU}$ youth. Conclusions: The current findings suggest that (i) maternal prenatal risks and fearless temperament showed a dose-response relationship with CP and CU (i.e., higher clustering of risks tended to relate to both higher levels and the co-occurrence of CU with $\mathrm{CP}$ ), and (ii) intervention programs that aim to improve behavioural outcomes may consider targeting specific temperamental features in both boys and girls. Keywords: Avon Longitudinal Study of Parents and Children, prenatal risks, early parenting, conduct problems, callous-unemotional traits.
\end{abstract}

There is growing evidence that conduct problem (CP) youth with callous-unemotional (CU) traits (e.g., lack of guilt, absence of empathy, callous use of others) show a more severe and chronic pattern of antisocial behaviour than other CP youth (Forsman, Lichtenstein, Andershed, \& Larsson, 2010; Rowe et al., 2010; Salekin, 2008), along with impaired neurological function (Blair, 2005; Jones, Laurens, Herba, Barker, \& Viding, 2009); they are also less distressed by the consequences of their behaviour (Pardini, Lochman, \& Frick, 2003) and are more difficult to treat than $\mathrm{CP}$ youth who do not show $\mathrm{CU}$ traits (Waschbusch, Carrey, Willoughby, King, \& Andrade, 2007). As a result, proposals have been submitted to the DSM-V Work Group on Disruptive Behavior Disorders for the addition of $\mathrm{CU}$ traits as a specifier to conduct disorder (i.e., CP/CU vs. CP) (Frick \& Moffitt, 2010). While the addition of such a diagnostic specification may aid in the identification of more homogeneous CP subtypes (Moffitt et al., 2008), a better understanding of the development of

Conflict of interest statement: No conflicts declared.
$\mathrm{CP} / \mathrm{CU}$ is critical for early identification and for successful treatment (Frick \& White, 2008).

For CP, known early risks include prenatal exposure to poverty, maternal psychopathology, substance use, and poor family relationships (Barker \& Maughan, 2009). During the first few years of life, harsh parenting and child maltreatment are particularly important for these problems (Jaffee, 2007). However, less is known about the importance of these risks for $\mathrm{CU}$ traits and studies to date have focused primarily on negative parenting (e.g., shouting in anger and smacking) and have been restricted to variation of $\mathrm{CP}$ and $\mathrm{CU}$ in late childhood and early adolescence as a function of negative and harsh parenting in mid-to-late childhood. Existing studies suggest that, despite the fact that harsh parenting has been shown to be a clear risk for the development of conduct problems, it does not appear to relate to the level of conduct problems in children with co-occurring CU traits (Lynam, Loeber, \& Stouthamer-Loeber, 2008; Oxford, Cavell, \& Hughes, 2003; Viding, Fontaine, Oliver, \& Plomin, 2009; Wooten, Frick, Shelton, \& Silverthorn, 1997). 
Children with $\mathrm{CP} / \mathrm{CU}$ are thought to be less responsive to parenting because $\mathrm{CP} / \mathrm{CU}$ is highly heritable - that is, criminogenic and psychopathological parental traits are transmitted to these children (Viding, Blair, Moffitt, \& Plomin, 2005). It is also thought that an early biological manifestation of $\mathrm{CU}$ is temperamental fearlessness, e.g., boldness, and deficits in response to cues of punishment/emotions in others (Frick \& White, 2008). These 'fearless' children are deemed less likely to achieve normative development of morality/conscience (Fowles, Kochanska, \& Murray, 2000; Posner \& Rothbart, 2000), and are thought to be less responsive to typical socialisation processes, including those that come from parents (Oxford et al., 2003; Viding et al., 2009). Yet, children with fearless temperaments have been shown to increase in $\mathrm{CP}$ with the experience of negative parenting, as well as to decrease in $\mathrm{CP}$ with the experience of positive and responsive parenting (Pardini, Lochman, \& Powell, 2007).

Despite recent advances in understanding the development of CP with and without CU, there is a dearth of investigations that assess early family- and child-based risk factors. Three areas of research remain high in potential for discovery. First, although $\mathrm{CP} / \mathrm{CU}$ has been shown to be highly heritable (Viding et al., 2005), most studies have not examined the source of heritability: the parents. In contrast to $\mathrm{CP}$ youth, parents of $\mathrm{CP} / \mathrm{CU}$ youth may show a heavier loading of psychopathology and criminogenic traits, and provide more compromised rearing environments (e.g., Loney, Huntenburg, Counts-Allan, \& Schmeelk, 2007; Viding et al., 2009). Second, we know of no published long-term longitudinal studies that have examined fearless temperament early in development. The reliability of this temperamental feature as a risk for subsequent $\mathrm{CU}$ and $\mathrm{CP}$ requires examination. Third, research has not yet examined the extent to which - in early childhood - positive or negative parenting may directly decrease or increase the expression of adolescent CP and/or CU (Frick \& Moffitt, 2010). It is important to study developmental precursors of $\mathrm{CU}$ traits that occur without $\mathrm{CP}$; for example, some research suggests that CU-only children may have experienced some protective effects (or fewer risks), buffering their vulnerability to expressing CP (Rowe et al., 2010). The fact that Pardini and colleagues (2007) reported that maternal warmth decreased CU in children suggests the importance of examining protective effects. Nevertheless, low levels of parental warmth, in addition to harsh and negative parenting, could also be conceptualised as an important risk factor, and such an assessment could help in characterising the family environment that might be risky for the later expression of $\mathrm{CU}$.

Prenatal and early postnatal risks are extremely influential in psychopathology across the life course (Shonkoff, Boyce, \& McEwen, 2009), and are advocated as important starting points for preventive interventions (Tremblay, 2010). Thus, we examined early developmental risks for adolescent $\mathrm{CP} / \mathrm{CU}$ and $\mathrm{CP}$ in a large epidemiological birth cohort. In line with previous research and theoretical models, we anticipated (i) that parents of $\mathrm{CP} / \mathrm{CU}$ youth would show greater psychopathology, criminal behaviours and substance use during pregnancy; (ii) that early fearless temperament (age 2) would increase the expression of CU more than CP in early adolescence, above and beyond the effects of parenting (positive or negative); but (iii) that each of these types of parenting might still directly affect $\mathrm{CP}$ and $\mathrm{CU}$; and (iv) an indirect pathway, whereby high maternal prenatal risk would increase fearless temperament, which in turn, would increase harsh parenting and decrease warm parenting, which would then lead to higher levels of adolescent $\mathrm{CP}$ and $\mathrm{CU}$.

\section{Method}

\section{Sample}

The Avon Longitudinal Study of Parents and Children (ALSPAC) is an ongoing population-based study designed to investigate the effects of a wide range of influences on the health and development of children. Pregnant women resident in the former Avon Health Authority in south-west England, having an estimated date of delivery between 1 April 1991 and 31 December 1992 , were invited to take part, resulting in a cohort of 14,541 pregnancies and 13,988 singletons/twins alive at 12 months of age. When compared to 1991 National Census Data, the ALSPAC sample was found to be similar to the UK population as a whole. Ethical approval for the study was obtained from the ALSPAC Law and Ethics Committee and the Local Research Ethics Committees. More detailed information on ALSPAC is available from the website: http://www.bris.ac.uk/alspac/.

\section{Measures}

Mothers completed questionnaires at multiple time points during pregnancy, and their child's infancy and childhood. Data on CP and CU were collected at age 13. The early parent-child predictors examined here were drawn from questionnaires completed between 8 weeks gestation and approximately 4 years of child age.

Socio-economic status (SES), marital status/cohabitation and age of mother at the birth of the child were each reported at 18 weeks postnatal. SES was coded via the Registrar General's social class scale (Office of Population Censuses and Surveys, 1991); we compared mothers in classes IV and V (low SES) with those in classes I, II and III. Marital status reflected: 1) no partner, no cohabitation, 2) not married but cohabiting, and 3) married and cohabiting. Age of mother $(M=24.34 ; S D=4.99)$ was dichotomised to contrast mothers who gave birth to the study child during the teens (e.g., age 19 and younger, coded 1) with all older mothers (coded 0).

Mother education was coded (at 32 weeks antenatal) as none, or CSE or vocational qualifications only (basic school-leaving/vocational qualifications). 
Cumulative prenatal risk is part of the Family Adversity Index (Bowen, Heron, Waylen, \& Wolke, 2005) that was collected at 8-32 weeks gestation. The Cumulative Prenatal Risk Index is a sum of 15 family-based risk factors across 8 risk domains: age of mother; housing adequacy; no educational qualifications; financial difficulties; poor partner relationships; maternal psychopathology; maternal substance abuse; and maternal criminal behaviour. Maternal psychopathology was measured via the Edinburgh Postnatal Depression Scale (Cox, Holden, \& Sagovsky, 1987; Murray \& Carothers, 1990) and the Crown-Crisp Depression Index (Birtchnell, Evans, \& Kennard, 1988); the Crown-Crisp Anxiety index (Birtchnell et al., 1988); and self-reported suicide attempts. eTable 1 further describes the elements of this measure, the 15 risks and their respective frequencies within ALSPAC.

Fearless temperament at age 2 was derived from items from the Approach and Adaptability subscales of the Carey Infant Scale (Carey \& McDevitt, 1978) that centred on (i) deficits in response to cues to punishment (i.e., Can be coaxed out of forbidden activity [reverse coded]; Won't reoffend if punished [reverse coded]; Goes to areas despite previous warnings), and (2) bold orientation to novel strangers/situations (i.e., Wary of strangers greater than 15 minutes [reverse coded]; First reacts to strangers with acceptance; Wary at first in new place [reverse coded]). At age 2 mothers reported on the

Table 1 Descriptive statistics for study variables by gender of the child

\begin{tabular}{|c|c|c|}
\hline & \multicolumn{2}{|c|}{ Entire sample } \\
\hline & Boys & Girls \\
\hline \multicolumn{3}{|l|}{ Family and maternal characteristics } \\
\hline Low SES (\%) & 8.27 & 10.29 \\
\hline CSE \& VOC & 20.40 & 20.83 \\
\hline Teen mother (\%) & 12.24 & 12.46 \\
\hline Police trouble (preg-4 years) $M S D$ & $.07(.33)$ & $.06(.33)$ \\
\hline Smoking pregnancy & 17.44 & 16.94 \\
\hline \multicolumn{3}{|l|}{ Fearless temperament (age 2) } \\
\hline Defiance to authority $M S D$ & $2.87(.79)$ & $2.74(.78)$ \\
\hline $\begin{array}{l}\text { Fearless to situations/ } \\
\text { strangers } M S D\end{array}$ & $3.08(.85)$ & $2.94(.85)$ \\
\hline \multicolumn{3}{|l|}{ Child exposures/experiences } \\
\hline $\begin{array}{l}\text { Maternal psychopathology } \\
\text { (pregnancy) }\end{array}$ & 21.81 & 23.42 \\
\hline $\begin{array}{l}\text { Maternal psychopathology } \\
\text { (0-2 years) }\end{array}$ & 19.04 & 20.27 \\
\hline $\begin{array}{l}\text { Maternal psychopathology } \\
\text { (2-4 years) }\end{array}$ & 13.58 & 14.19 \\
\hline Harsh parenting $M S D$ (2 years) & $6.10(1.73)$ & $5.81(1.71)$ \\
\hline Harsh parenting $M S D$ (4 years) & $7.05(1.75)$ & $6.67(1.75)$ \\
\hline Warm parenting $M S D$ (2 years) & $3.90(026)$ & $3.91(.23)$ \\
\hline Warm parenting $M S D$ (4 years) & $3.74(.64)$ & $3.79(.64)$ \\
\hline \multicolumn{3}{|l|}{ Partner cruelty to mother } \\
\hline 0-2 years & 13.17 & 13.32 \\
\hline $2-4$ years & 13.43 & 13.38 \\
\hline \multicolumn{3}{|l|}{ Maternal attitude towards child } \\
\hline Does not enjoy child $M S D$ & $1.31(.54)$ & $1.30(.53)$ \\
\hline Feels fulfilled by child $M S D$ & $3.86(.49)$ & $3.87(.48)$ \\
\hline \multicolumn{3}{|l|}{ Adolescent outcomes (age 13) } \\
\hline $\begin{array}{l}\text { Callous-unemotional traits } \\
M S D\end{array}$ & $10.71(3.21)$ & $10.78(3.19)$ \\
\hline Conduct problems $M S D$ & $1.23(1.41)$ & $1.17(1.40)$ \\
\hline
\end{tabular}

Note: Mean scores are presented in the raw metric. extent to which their child showed these behaviours ( 1 = rarely to 5 =almost always $)$. We examined the reliability of the fearless temperament construct within a second-order confirmatory factor structure (i.e., the variance common to 'deficits in response to punishment cues' and 'boldness') and found acceptable fit to the data: $\chi^{2}(59)=465.029, p<.001 ;$ CFI $=.96$, TLI $=.96$; RMSEA $=.05(90 \%$ CI $=.04-.05)$.

Harsh parenting at ages 2 and 4 was assessed by the mothers answering, 'When you are at home with your child, how often do you do the following': 1) shout at him/her, and 2) slap him/her. Response scale (reversed coded) was from $1=$ every day to $5=$ rarely $/$ never. Latent confirmatory analysis showed acceptable reliability for age 2 and age 4 respectively $\left[\chi^{2}(2)=4.11\right.$, $12.31 ; \mathrm{CFI}=.99, .99, \mathrm{TLI}=.99 .99 ; \mathrm{RMSEA}=.02,04$ $(90 \% \mathrm{CI}=.01,02-.04,07)]$.

Warm parenting at age 2 was measured by the mothers rating the extent to which they: 1) really love the toddler, 2) have pleasure in watching the child grow, and 3) feel that the child gives [them] great joy. The response scale (reverse coded) was from 1 = feel exactly to $5=$ feel never. Cronbach's alpha indicated good reliability (.71). At 4 years, warm parenting was assessed with the following five items rating how much the mother: 1) sings to, 2) reads to, 3) plays with toys, 4) plays games, and 5) engages the child in physical play. The response scale (reverse coded) was from $1=$ nearly every day to $5=$ never). Cronbach's alpha indicated good reliability (.74).

Conduct problems at ages 7,10 and 13 years were measured by mother reports on the Strengths and Difficulties Questionnaire (Goodman, 2001), with the following five items: 1) Often has temper tantrums or hot tempers; 2) Generally obedient, usually does what adults request; 3) Often fights with other children or bullies them; 4) Often lies or cheats; and 5) Steals from home, school or elsewhere. We created binary $(0=$ not high risk/ 1 = high risk) indicators at each age, based on national norms established for 5-10-year-old boys and girls in England and Wales (Meltzer, Gatward, Goodman, \& Ford, 2000). The cutoffs used here (top $10 \%$ ) are strong predictors of DSM-based (American Psychiatric Association, 1994) diagnoses of conduct disorder (Goodman, 2001), and of oppositional defiant disorder (ODD), attention deficit/hyperactivity disorder (ADHD) and anxiety (Barker, Oliver, \& Maughan, 2010) in late childhood and adolescence.

Callous and unemotional traits at age 13 were measured by mother reports on a 6-item questionnaire (Moran, Ford, Butler, \& Goodman, 2008). The following items were rated as 'not true', 'partly true' or 'certainly true': 1) Makes a good impression at first but people tend to see through him/her after they get to know him/ her; 2) Shallow or fast-changing emotions; 3) Is usually genuinely sorry if $\mathrm{s} /$ he has hurt someone or acted badly; 4) Can seem cold-blooded or callous; 5) Keeps promises; and 6) Genuine in his/her expression of emotions. These items were chosen on the basis of factor analyses of scales measuring CU traits (Frick, Bodin, \& Barry, 2000; Frick, O’Brien, Wootton, \& McBurnett, 1994). This questionnaire correlated highly $(r=.81)$ with the CU scale of the Antisocial Process Screening Device in 182 children displaying antisocial behaviour aged 9-17 (Moran et al., 2009). In 
the follow-back portion of the analysis, we used a cutoff of the top $10 \%$ to define those high in CU traits. This cutoff is similar to that used by Rowe et al. (2010) (top $5 \%$ ) on a national UK cohort study. We note here that increasing the level of the cutoff did not result in differential risk predictions.

\section{Attrition and missing data}

Participants with data for either the CU or CP scales were selected for the analysis. This resulted in a sample of 6,673 youth (boys $=3,367$; girls $=3,306$ ). In a multivariate model, we tested the extent to which the study variables (Table 1) predicted exclusion from the current analysis. Mothers with low educational attainment $(\mathrm{OR}=1.47)$, from low SES circumstances $(\mathrm{OR}=1.42)$ and high levels of cumulative maternal prenatal risk $(\mathrm{OR}=1.13)$ were likely to be lost to attrition. It is important to note that these variables were included in the present analysis.

\section{Analysis}

The analyses proceeded in three steps. In the first step, we examined a confirmatory factor analysis (CFA) of $\mathrm{CP}$ and CU. In Step 2, the CP and CU factors were predicted by (i) prenatal stress, (ii) age 2 fearless temperaments, and (iii) age 4 harsh parenting and warm parenting. In this step, we also examined indirect effects; that is, the extent to which $\mathrm{CP}$ and $\mathrm{CU}$ was predicted by prenatal stress, and/or by fearless temperament, via harsh (or warm) parenting. Indirect effects were bootstrapped 5,000 times with bias-corrected confidence intervals. In Step 3, we classified the boys and girls into $\mathrm{CP} / \mathrm{CU}, \mathrm{CP}$ and CU groups via raw scales scores (top 10\%) and used a follow-back strategy to further 'unpack' prenatal, early postnatal and temperamental risks within the first four years of life.

Steps 1 and 2 were conducted in Mplus Version 5.21 (Muthén \& Muthén, 1998-2009). To correct for nonnormal distributions maximum likelihood estimation with robust standard errors (MLR) was used. Missing data were accounted for by full information maximum likelihood estimation. Model fit was determined through the Comparative Fit Index and Tucker-Lewis Index (CFI $\&$ TLI; acceptable fit $\geq .90$ ) (Bentler $\&$ Bonett, 1980) and root mean square error of approximation (RMSEA; acceptable fit $\leq$.08) (Browne \& Cudeck, 1993). Step 3 was conducted in PROC CATMOD in SAS v.9.1 (SAS Institute Inc., 2005).

\section{Results}

\section{Step 1: Factor structure of $C U$ and $C P$}

The correlated confirmatory factor analysis of $\mathrm{CU}$ and $\mathrm{CP}$ fit the data adequately: $\chi^{2}(68)=679.25$, $p<.001 ; \mathrm{CFI}=.93, \mathrm{TLI}=.91 ; \mathrm{RMSEA}=.05(90 \%$ $\mathrm{CI}=.05-.06)$. The loadings for CU (boys: .49-.65; girls: .49-.65) and CP (boys: .29-.65; girls: .37-.60) were adequate. CU and CP were similarly and significantly correlated for boys $(r=.67, p<.001)$ and for girls $(r=.68, p<.001)$.

\section{Step 2: Prediction of $C P$ and $C U$}

In Step 2, we predicted CP and CU by the early risks (see Figure 1; parameter estimates: boys/girls). Four findings are highlighted. First, higher levels of prenatal risk were associated with fearless temperament (boys not girls) and $\mathrm{CP}$ and $\mathrm{CU}$ at age 13 (stronger effect for girls vs. boys). Second, for both boys and girls, fearless temperament at age 2 was associated with higher levels of CP and CU. Third, harsh parenting at age 4 was associated with increased $\mathrm{CP}$ and $\mathrm{CU}$ at age 13 (for boys not girls; these estimates, however, did not significantly differ between boys and girls). Fourth, at age 2, for boys and girls, harsh parenting and fearless temperament correlated moderately, suggesting that increase in one leads to an increase in the other.

Table 2 contains the indirect pathways to adolescent $\mathrm{CP}$ and $\mathrm{CU}$. For boys only the following two pathways were observed: 1) prenatal stress predicted fearless temperament at age 2, which, in turn, was associated with elevated levels of harsh parenting at age 4 that further related to increased $\mathrm{CP}$ and $\mathrm{CU}$ at age $13 ; 2$ ) fearless temperament at age 2 was associated with an increase in levels of harsh parenting at age 4 , which in turn related to increased $\mathrm{CP}$ and $\mathrm{CU}$ at age 13. Sex differences in the indirect pathways included only the pathways that contained the maternal prenatal risks.

\section{Step 3: Follow-back analysis}

In the final step, we classified the boys and girls according to their scores on the $\mathrm{CU}$ and $\mathrm{CP}$ scales, and 'unpacked' the various risks. Of the 3,367 boys, $79.14 \%$ were low in $\mathrm{CU}$ and $\mathrm{CP}, 8.49 \%$ were $\mathrm{CP}$, $6.85 \% \mathrm{CU}$, and $5.52 \% \mathrm{CP} / \mathrm{CU}$. Of the 3,306 girls, $79.56 \%$ were low, $7.26 \% \mathrm{CP}, 7.53 \% \mathrm{CU}$, and $5.65 \%$ $\mathrm{CP} / \mathrm{CU}$. In reminder, the cutoff scores used here are strong predictors of conduct disorder diagnoses (Barker et al., 2010), and represent the top 10\% of girls and boys (respectively) in the SDQ conduct problems subscale, and the top $10 \%$ of girls and boys in the $\mathrm{CU}$ scale. In Figure 2, for $\mathrm{CP} / \mathrm{CU}$ boys, approximately $60 \%$ were at risk for conduct disorder at ages 7 and 10 years. For CP/CU girls, the risk for conduct disorder slightly increased and was also near $60 \%$ by age 10 . Of interest, the largest difference between $\mathrm{CP}$ and $\mathrm{CU}$ in risk for conduct disorder, favouring $\mathrm{CP}$ girls, was at age 7 .

Prenatal and early postnatal risks. Table 3 presents the early risks for boys in the four groups. Four results are highlighted here. First, compared to the Low youth, the CP/CU were higher in nearly all early risk factors. Second, compared to the $\mathrm{CP}$, the $\mathrm{CP} / \mathrm{CU}$ were from lower SES circumstances, and experienced greater levels of maternal psychopathology, harsh parenting, partner cruelty towards the mother 


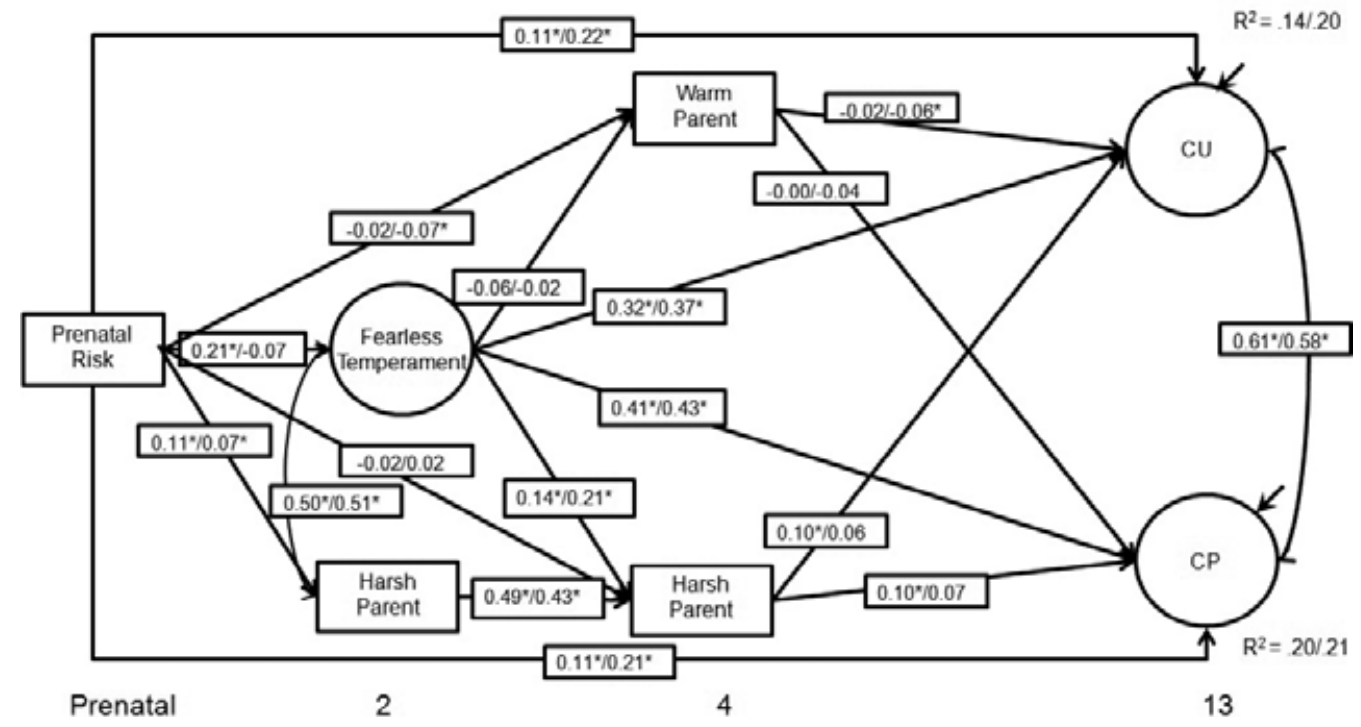

Figure 1 Standardised path estimates for prenatal, age 2 and age 4 predictors of $\mathrm{CU}$ and $\mathrm{CP}$ at age 13; * $=p \leq .05$; paths are shown for boys/girls; the observed indicators for the latent variables (circles) are not shown

Table 2 Significant indirect effects of prenatal maternal risk, fearless temperament and parenting on male CU and CP

\begin{tabular}{lcccccc}
\hline & & & & & \multicolumn{2}{c}{$95 \%$ CI } \\
\cline { 3 - 7 } Prenatal & Age 2 & Age 4 & Age 13 & Estimate & Low & High \\
\hline Maternal Risk [+] & Temperament [+] & Harsh Parenting [+] & CP [+] & .003 & .001 & .006 \\
\multirow{2}{*}{ Maternal Risk [+] } & Temperament [+] & Harsh Parenting [+] & CP [+] & .016 & .005 & .030 \\
& Temperament [+] & Harsh Parenting [+] & CU [+] & .003 & .001 & .006 \\
& Temperament [+] & Harsh Parenting [+] & CU [+] & .014 & .006 & .029 \\
\hline
\end{tabular}

Note: $[+]$ = increasing; $\mathrm{CP}=$ Conduct problems; $\mathrm{CU}=$ Callous-unemotional; all effects are significant at $p<.05$.

and the mother endorsing that they did not enjoy their child. Third, the CP differed from the CU in that these boys experienced lower levels of maternal psychopathology, but also higher levels of mothers not enjoying their child. Fourth, compared to the CU and $\mathrm{CP}$, for $\mathrm{CP} / \mathrm{CU}$ boys, fearless temperament was characterised by low response to punishment cues of the mother.

Table 4 contains the same risks for girls. The first three patterns of results were highly similar to those of the boys (see above); however, unlike the boys - for the fourth result - fearless temperament for the girls manifested as assertiveness to new situations and unfamiliar adults (i.e., boldness).

\section{Discussion}

The present study is the first epidemiological investigation to show that $\mathrm{CP} / \mathrm{CU}$ and $\mathrm{CP}$ in early adolescence are associated with maternal prenatal risk, early child fearless temperament and harsh parenting. As reviewed below, these findings extend the existing understanding of early developmental risks for $\mathrm{CP} / \mathrm{CU}$ and $\mathrm{CP}$ in three main ways.

First, we show that, in early adolescence, not only do $\mathrm{CP} / \mathrm{CU}$ boys and girls have the highest risk for early onset conduct disorder $(\sim 60 \%$ at ages 7 and 10), but these youth also tend to have slightly more early family-based risks compared to $\mathrm{CP}$ and CU. For instance, $\mathrm{CP} / \mathrm{CU}$ tended to be associated with higher levels of maternal psychopathology, harsh parenting and low parental warmth. A mother that reported not 'enjoying' the child differentiated the CP/CU from the $\mathrm{CP}$ and $\mathrm{CU}$ for female adolescents. Moreover, and perhaps surprisingly, our measure of warm parenting had little positive effect on $\mathrm{CU}$ or $\mathrm{CP}$, although, for girls, it did relate to a slight reduction in $\mathrm{CU}$ traits. We note here, however, that the strongest parent-child result - for boys and girls - was a moderate $(r \geq .50)$ within time (age 2) correlation between harsh parenting and fearless temperament. This result suggests that, early in development, harsh parenting and fearless temperament may work in a bidirectional manner.

Second, the present findings appear at least partially consistent with a biological or inherited basis for CP and CU (Forsman et al., 2010; Viding et al., 2005). That is, for both genders, prenatal maternal risks and fearless temperament were prospectively associated with an increase in $\mathrm{CP}$ and $\mathrm{CU}$ above and beyond influence of harsh parenting. However, study results also indicated what may be important sex-differences in certain risk effects -i.e., prenatal risks had a larger direct impact on elevated adolescent CU and CP for girls, whereas - for boys - prenatal risks appeared to initiate an indirect pathway to higher levels of CP and $\mathrm{CU}$, via increasing fearless temperament and harsh 

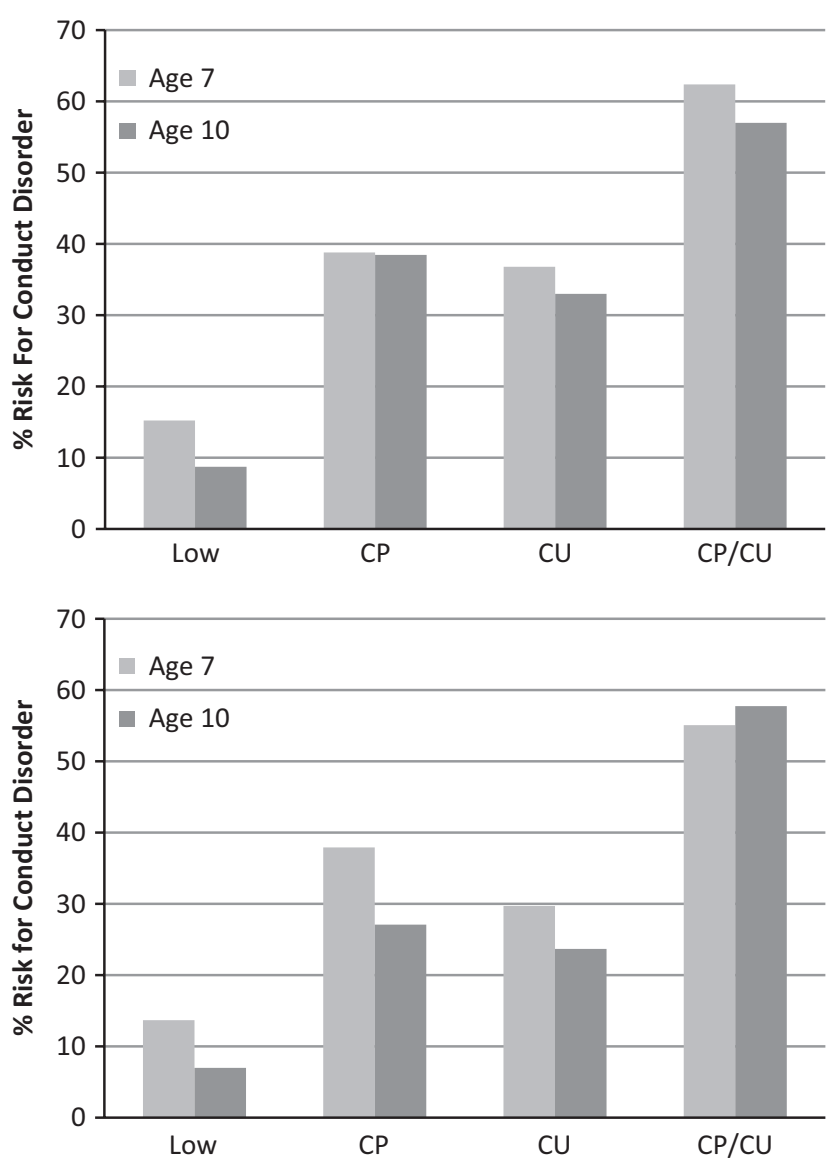

Figure 2 Conduct disorder risk at ages 7 and 10 for boys (top) and girls (bottom) in the CU-CP groups

parenting. Of interest, in the follow-back analysis, different features of the fearless temperament differentiated $\mathrm{CU} / \mathrm{CP}$ from $\mathrm{CU}$ and $\mathrm{CP}$, for boys (i.e., lack of sensitivity to punishment) and girls (i.e., heightened boldness towards novel situations and strangers). Although speculative, this sex-difference may support the idea that $\mathrm{CU}$ girls may express their antisocial tendencies via disinhibited social engagement (Taylor et al., 2000) whereas CU in boys is expressed via callous/fighting and general high levels of $\mathrm{CP}$ behaviours.

Third, although CU-only is currently not a proposed diagnostic category for the DSM-V (Frick \& Moffitt, 2010), the present study design afforded the opportunity to examine the extent to which these youth may have experienced protective factors (or less risk) that may have buffered their presumed vulnerability for expressing CP. Like previous research, however, we found the $\mathrm{CP}$ and $\mathrm{CU}$ groups to be somewhat similar in risk and in levels of antisocial behaviour (Frick \& White, 2008). Indeed, although the $\mathrm{CP}$ group demonstrated higher risk for conduct disorder at both age 7 and age 10 than the $\mathrm{CU}$ group, it is important to note that the CU group was also high in this risk. It is plausible that this suggests that these groups engage in different conduct problem behaviours in adolescence, and/or are at risk for different forms of psychopathology (Salekin, Rosenbaum, Lee, \& Lester, 2009).
The many strengths of the current study, such as its large sample size, broad scope and extended longitudinal focus, are also related to certain limitations common to samples of this kind. In particular the measures were brief and could have benefited from more detail. The present results should be interpreted in the context of eight main limitations. First, the measure of fearless temperament - as constructed in this study at age 2 - included lack of sensitivity to punishment and boldness towards novel situations/stranger; unfortunately, however, indicators of emotional impairment (such as failure to create emotional bonds with caretaker(s) and/or other children), also considered part of the fearless temperament construct, were not available in ALSPAC at age 2. Second, we did not have a measure of fearless temperament at age 4, which disallowed the examination of the extent to which harsh parenting increased fearless temperament (Larsson, Viding, \& Plomin, 2008) - an important avenue for future research. Indeed, a substantial correlation between harsh parenting and fearlessness at age 2 suggests a strong possibility of such reciprocal effects within the first few years of a child's life. Third, most of our measures were based on maternal reports, raising the possibility of shared method variance. Fourth, although the mothers and children of ALSPAC represent a broad spectrum of SES backgrounds, the sample includes relatively low rates of ethnic minorities; the present results will need replication with more ethnically diverse samples. Fifth, we focused on prenatal and early postnatal risks, assessed prior to child age 4. Later child-based environmental risks, such as association with deviant peers (Lacourse et al., 2006) and exposure to the criminal justice system (Gatti, Tremblay, \& Vitaro, 2009), may also contribute to differentiating the $\mathrm{CP} / \mathrm{CU}, \mathrm{CP}$ and $\mathrm{CU}$ groups, and are important targets for future study. Sixth, we examined CP and CU at age 13, but a more comprehensive examination that includes repeated measurements of $\mathrm{CU}$ would be valuable. Indeed, though high levels of $\mathrm{CU}$ have been shown to be fairly stable (Frick, Kimonis, Dandreaux, \& Farell, 2003), both increases and decreases in CU have also been shown, and this is an important area for future investigation (Salekin et al., 2009). Seventh, replications of the current results are needed within genetically sensitive longitudinal research designs that can disambiguate gene-environment processes (Viding et al., 2009). Eighth, and finally, like most large longitudinal cohorts, ALSPAC has faced attrition over time. For example, as expected, younger and more socially disadvantaged mothers were more likely to be lost to follow-up. Because these predictors of attrition are also predictors of child conduct problems, our sample almost certainly under-represents children with the most severe difficulties. Of note, a recent study based on the ALSPAC cohort showed that although attrition affected prevalence 


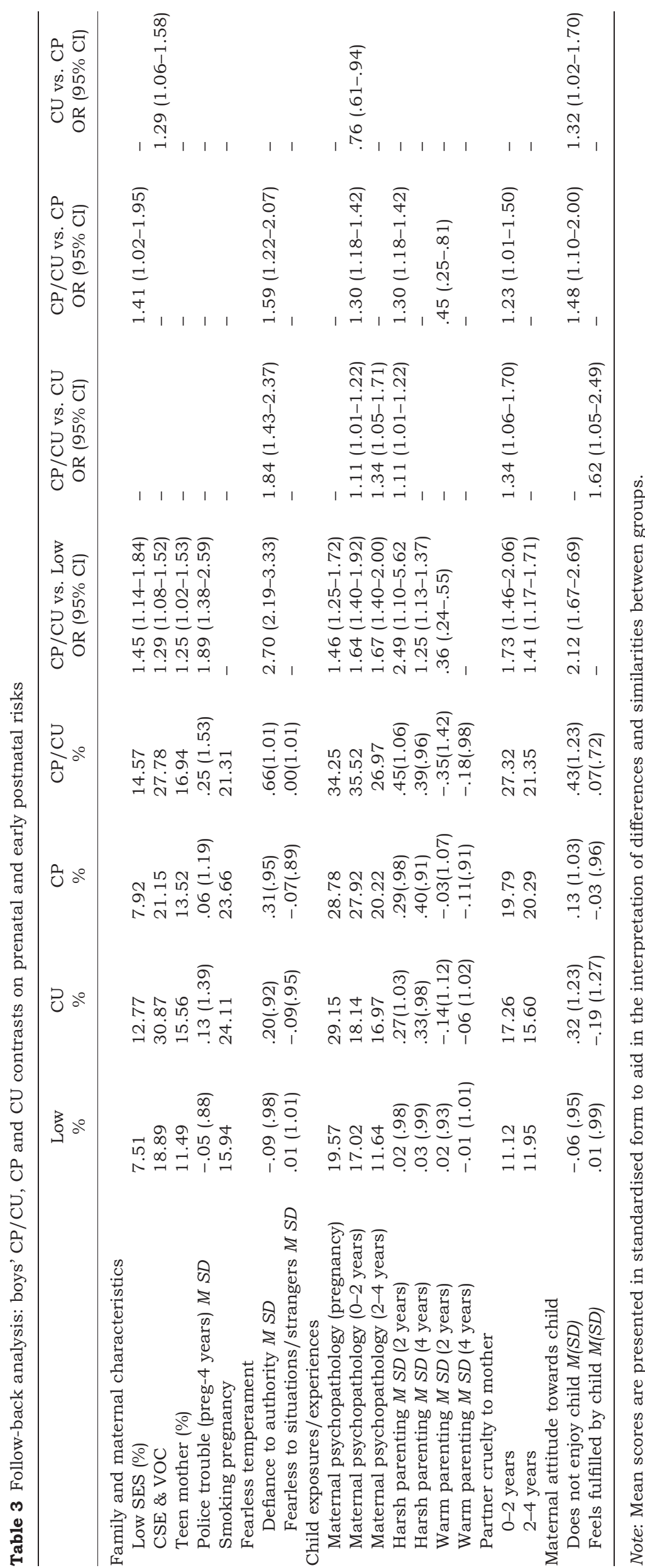




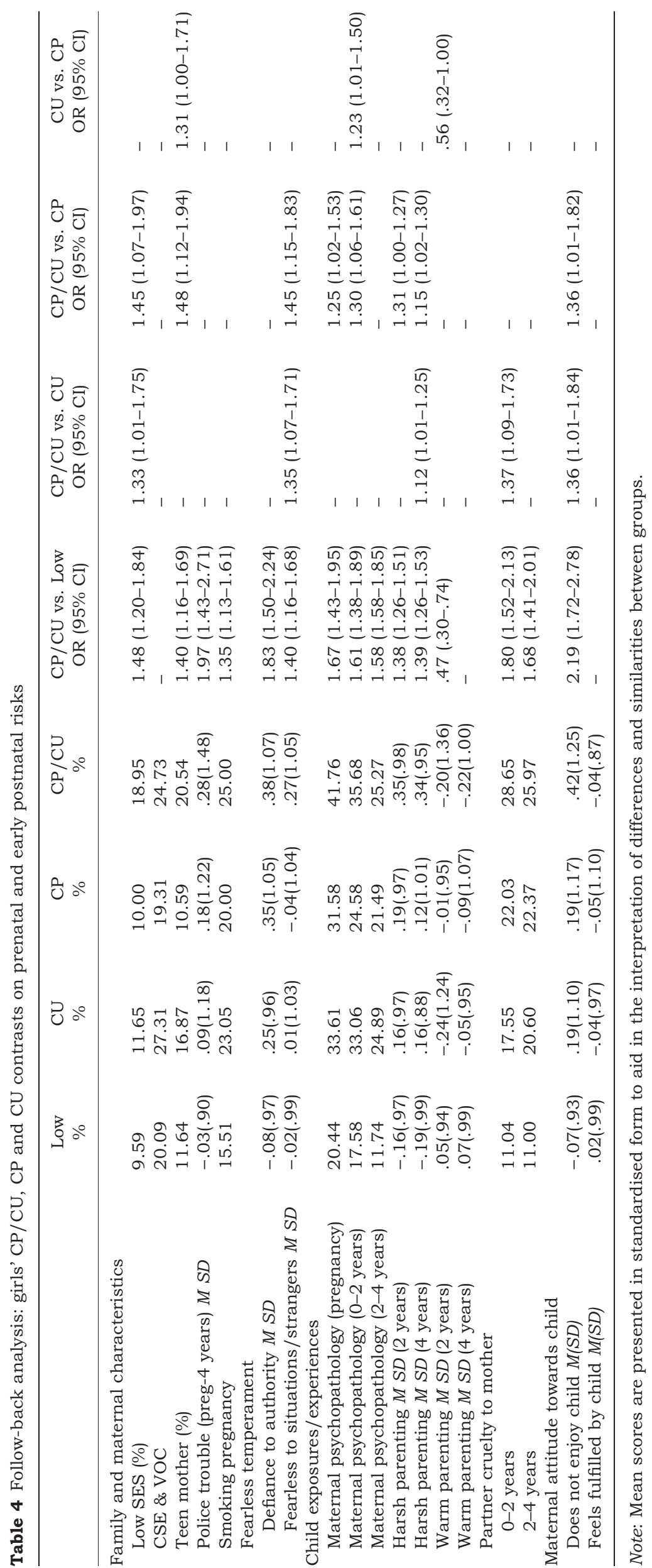


rates of antisocial behaviours and related disorders, associations between risks and outcomes remained intact, though conservative estimates of the likely true effects (Wolke et al., 2009).

\section{Conclusion}

The present study is the first, to our knowledge, to examine early prenatal and postnatal predictive risk differences in adolescent $\mathrm{CP} / \mathrm{CU}, \mathrm{CP}$, and $\mathrm{CU}$. A growing body of research suggests that intensive, individualised treatments have the potential to lift the pessimism associated with treating $\mathrm{CP}$ children with high levels of CU traits, and to be successful (Caldwell, Skeem, Salekin, and Van Rybroek, 2006; Salekin, 2010). Clinical methods for addressing child characteristics are in their infancy, and, although the importance of using multifaceted approaches is increasingly recognised (Scott \& Dadds, 2009), there is some way to go in understanding characteristics that may be important targets. Using a large longitudinal cohort, we highlight that (i) for boys and girls, the strongest effect from the parents is best described as a bidirectional process early in development (age 2) where higher levels of harsh parenting associated with increased expression of fearless temperament and vice versa; but that (ii) fearless temperament still directly increased adolescent $\mathrm{CP}$ and $\mathrm{CU}$, above and beyond early parenting. We therefore suggest that, in conjunction with risk factors associated with the caregiving environment, specific temperamental features are important targets for intervention programs; our results also indicate that gender-specific approaches may be important.

We also propose that future research efforts aimed at distinguishing $\mathrm{CU}$ and $\mathrm{CP}$ may consider more fully the CP-only youth, thought to be more emotionally and behaviourally dysregulated in comparison with the CU youth, and potentially more influenced by poor parenting and other contextual risks. A balanced examination of risks and individual characteristics that are believed to differ between these two types of $\mathrm{CP}$ youth may not only aid in understanding these subtypes of CP (Moffitt et al., 2008), but may also translate into a sound information-base for the DSM-V Work Group on Disruptive Behavior Disorders.

\section{Supporting information}

Additional Supporting Information may be found in the online version of this article:

Table S1 Prenatal Cumulative Risk Index.

Please note: Blackwell Publishing are not responsible for the content or functionality of any supplementary materials supplied by the authors. Any queries (other than missing material) should be directed to the corresponding author for the article.

\section{Acknowledgements}

We are extremely grateful to all the families who took part in this study, the midwives for their help in recruiting them, and the whole ALSPAC team, which includes interviewers, computer and laboratory technicians, clerical workers, research scientists, volunteers, managers, receptionists and nurses. The UK Medical Research Council, the Wellcome Trust and the University of Bristol provide core support for ALSPAC. Access to the ALSPAC data was funded by a grant to Barbara Maughan from the UK Medical Research Council (MRC G0500953). Edward D. Barker had full access to all of the data in the study and takes responsibility for the integrity of the data and the accuracy of the data analysis.

\section{Correspondence to}

Edward D. Barker, Department of Psychological Science, Birkbeck, University of London, Malet Street, London, WC1E 7AX, UK; Email: t.barker@, bbk.ac.uk

\section{Key points}

- Risks prospectively associated with higher levels of conduct problems also increase levels of callous-unemotional traits.

- Risks can be identified both during gestation (e.g., cumulative risks, including maternal psychopathology) and early in development (e.g., harsh parenting).

- Fearless temperament at age 2 is prospectively associated with increased levels of conduct problems and callous-unemotional traits, above and beyond prenatal maternal risks and parenting.

- Fearless temperament in boys manifested as lower response to punishment cues, while for girls this temperament was indexed by boldness towards novel situations and strangers.

- Intervention programs that aim to improve behavioural outcomes may consider targeting specific temperamental features such as fearlessness. 


\section{References}

American Psychiatric Association. (1994). Diagnostic and statistical manual of mental disorders, fourth edition. Washington, DC: American Psychiatric Association.

Barker, E.D., \& Maughan, B. (2009). Differentiating earlyonset persistent versus childhood-limited conduct problem youth. American Journal of Psychiatry, 166, 900-908.

Barker, E.D., Oliver, B.R., \& Maughan, B. (2010). Co-occurring problems of early onset persistent, childhood limited, and adolescent onset conduct problem youth. Journal of Child Psychology and Psychiatry, 51, 1217-1226.

Bentler, P.M., \& Bonett, D.G. (1980). Significance tests and goodness of fit in the analysis of covariance structures. Psychological Bulletin, 88, 588-606.

Birtchnell, J., Evans, C., \& Kennard, J. (1988). The total score of the Crown Crisp experiential index: A useful and valid measure of psychoneurotic pathology. British Journal of Medical Psychology, 61, 255-266.

Blair, R. (2005). Applying a cognitive neuroscience perspective to the disorder of psychopathy. Development and Psychopathology, 17, 865-891.

Bowen, E., Heron, J., Waylen, A., \& Wolke, D. (2005). Risk for domestic violence during and after pregnancy: Findings from a British longitudinal study. British Journal of Obstetrics and Gynaecology, 112, 1083-1089.

Browne, M.W., \& Cudeck, R. (1993). Alternative ways of assessing model fit. In K.A. Bollen, \& J.S. Long, (Eds), Testing structural equation models (pp. 136-162. Newbury Park, CA: Sage.

Caldwell, M., Skeem, J., Salekin, R., \& Van Rybroek, G. (2006). Treatment response of adolescent offenders with psychopathy features: A 2-year follow-up. Criminal Justice and Behavior, 33, 571-596.

Carey, W.B., \& McDevitt, S.C. (1978). Revision of the Infant Temperament Questionnaire. Pediatrics, 61, 735-739.

Cox, J.L., Holden, J.M., \& Sagovsky, R. (1987). Detection of postnatal depression: The development of the Edinburgh 10-item Postnatal Depression Scale. British Journal of Psychiatry, 150, 782-786.

Forsman, M., Lichtenstein, P., Andershed, H., \& Larsson, H. (2010). A longitudinal twin study of the direction of effects between psychopathic personality and antisocial behaviour. Journal of Child Psychology and Psychiatry, 51, 39-47.

Fowles, D.C., Kochanska, G., \& Murray, K. (2000). Electrodermal activity and temperament in preschool children. Psychophysiology, 37, 777-787.

Frick, P.J., Bodin, S.D., \& Barry, C.T. (2000). Psychopathic traits and conduct problems in community and clinic-referred samples of children: Further development of the psychopathy screening device. Psychological Assessment, 12, 382-393.

Frick, P.J., Kimonis, E.R., Dandreaux, D.M., \& Farell, J.M. (2003). The 4 year stability of psychopathic traits in nonreferred youth. Behavioral Sciences and the Law, 21, 713736.

Frick, P.J., \& Moffitt, T.E. (Writer). (2010). A proposal to the DSM-V Childhood Disorders and the ADHD and Disruptive Behavior Disorders Work Groups to include a specifier to the diagnosis of conduct disorder based on the presence of callous-unemotional traits: American Psychiatric Association.

Frick, P.J., O’Brien, B.S., Wootton, J.M., \& McBurnett, K. (1994). Psychopathy and conduct problems in children. Journal of Abnormal Psychology, 103, 700-707.

Frick, P.J., \& White, S.F. (2008). Research Review: The importance of callous-unemotional traits for developmental models of aggressive and antisocial behavior. Journal of Child Psychology and Psychiatry, 49, 359-375.

Gatti, U., Tremblay, R.E., \& Vitaro, F. (2009). Iatrogenic effect of juvenile justice. Journal of Child Psychology and Psychiatry, 50, 991-998.
Goodman, R. (2001). Psychometric properties of the Strengths and Difficulties Questionnaire (SDQ). Journal of the American Academy of Child and Adolescent Psychiatry, 40, 1337-1345.

Jaffee, S.R. (2007). Sensitive, stimulating caregiving predicts cognitive and behavioral resilience in neurodevelopmentally at-risk infants. Development and Psychopathology, 19, 631647

Jones, A.P., Laurens, K.L., Herba, C., Barker, G., \& Viding, E. (2009). Amygdala hypoactivity to fearful faces in boys with conduct problems and callous-unemotional traits. American Journal of Psychiatry, 166, 95-102.

Lacourse, E., Nagin, D.S., Vitaro, F., Cote, S., Arseneault, L., \& Tremblay, R.E. (2006). Prediction of early onset deviant peer group affiliation: A 12-year longitudinal study. Archives of General Psychiatry, 63, 562-568.

Larsson, H., Viding, E., \& Plomin, R. (2008). Callous-unemotional traits and antisocial behavior - genetic, environmental, and early parenting characteristics. Criminal Justice and Behavior, 35, 197-211.

Loney, B.R., Huntenburg, A., Counts-Allan, C., \& Schmeelk, K.M. (2007). A preliminary examination of the intergenerational continuity of maternal psychopathic features. Aggressive Behavior, 33, 14-25.

Lynam, D.R., Loeber, R., \& Stouthamer-Loeber, M. (2008). The stability of psychopathy from adolescence into adulthood: The search for moderators. Criminal Justice and Behavior, 35, 228-243.

Meltzer, H., Gatward, R., Goodman, R., \& Ford, F. (2000). Mental health of children and adolescents in Great Britain. London: The Stationery Office.

Moffitt, T.E., Arseneault, L., Jaffee, S., Kim-Cohen, J., Koenen, K.C., Odgers, C.L., et al. (2008). Research Review: DSM-V conduct disorder: Research needs for an evidence base. Journal of Child Psychology and Psychiatry, 49, 3-33.

Moran, P., Ford, T., Butler, G., \& Goodman, R. (2008). Callous and unemotional traits in children and adolescents living in Great Britain. British Journal of Psychiatry, 192, 65-66.

Moran, P., Rowe, R., Flach, C., Briskman, J., Ford, T., Maughan, B., et al. (2009). Predictive value of callousunemotional traits in a large community sample. Journal of the American Academy of Child and Adolescent Psychiatry, 48, 1079-1084.

Murray, L., \& Carothers, A. (1990). The validation of the Edinburgh Post-natal Depression Scale on a community sample. British Journal of Psychiatry, 157, 288-290.

Muthén, L.K., \& Muthén, B. O. (1998-2009). Mplus. Statistical analyses with latent variables. User's guide (5.21 edn). Los Angeles, CA: Muthén \& Muthén.

Oxford, M., Cavell, T.A., \& Hughes, J.N. (2003). Callous/ unemotional traits moderate the relation between ineffective parenting and child externalizing problems: A partial replication and extension. Journal of Clinical Child and Adolescent Psychology, 32, 577-585.

Pardini, D., Lochman, J.E., \& Powell, N. (2007). The development of callous-unemotional traits and antisocial behavior in children: Are there shared and/or unique predictors? Journal of Clinical Child and Adolescent Psychology, 36, 319-333.

Pardini, D.A., Lochman, J.E., \& Frick, P.J. (2003). Callous/ unemotional traits and social-cognitive processes in adjudicated youths. Journal of the American Academy of Child and Adolescent Psychiatry, 42, 364-371.

Posner, M.I., \& Rothbart, M.K. (2000). Developing mechanisms of self-regulation. Development and Psychopathology, 12, 427-441.

Rowe, R., Maughan, B., Moran, P., Ford, T., Briskman, J., \& Goodman, R. (2010). The role of callous and unemotional traits in the diagnosis of conduct disorder. Journal of Child Psychology and Psychiatry, 51, 688-695.

Salekin, R.T. (2008). Psychopathy and recidivism from midadolescence to young adulthood: Cumulating legal problems 
and limiting life opportunities. Journal of Abnormal Psychology, 117, 386-395.

Salekin, R.T. (2010). Treatment of child and adolescent psychopathy: Focusing on change. In R.T. Salekin, \& D.R. Lynam, (Eds), Handbook of child and adolescent psychopathy (pp. 343-373). New York: Guilford Press.

Salekin, R.T., Rosenbaum, J., Lee, Z., \& Lester, W.S. (2009). Child and adolescent psychopathy: Like a painting by Monet. Youth Violence and Juvenile Justice, 7, 239-255.

SAS Institute Inc. (2005). SAS/STAT user's guide, version 9.1 (4th edn, vol. 2). Cary, NC: SAS Institute Inc.

Scott, S., \& Dadds, M.R. (2009). Practitioner Review: When parent training doesn't work: Theory-driven clinical strategies. Journal of Child Psychology and Psychiatry, 50, 14411450.

Shonkoff, J.P., Boyce, W.T., \& McEwen, B.S. (2009). Neuroscience, molecular biology, and the childhood roots of health disparities: Building a new framework for health promotion and disease prevention. Journal of the American Medical Association, 301, 2252-2259.

Office of Population Censuses and Surveys (1991). Standard Occupational Classification. Volume 3. London: HMSO.

Taylor, S.E., Klein, L.C., Lewis, B.P., Gruenewald, T.L., Gurung, R.A.R., \& Updegraff, J.A. (2000). Biobehavioral responses to stress in females: Tend-and-befriend, not fightor-flight. Psychological Review, 107, 411-429.

Tremblay, R.E. (2010). Developmental origins of disruptive behaviour problems: The 'original sin' hypothesis, epigenetics and their consequences for prevention. Journal of Child Psychology and Psychiatry, 51, 341-367.
Viding, E., Blair, R.J.R., Moffitt, T.E., \& Plomin, R. (2005). Evidence for substantial genetic risk for psychopathy in 7-year-olds. Journal of Child Psychology and Psychiatry, 46, 592-597.

Viding, E., Fontaine, N.M.G., Oliver, B.R., \& Plomin, R. (2009). Negative parental discipline, conduct problems and callous-unemotional traits: A monozygotic twin differences study. British Journal of Psychiatry, 195, 414419.

Waschbusch, D.A., Carrey, N.J., Willoughby, M.T., King, S., \& Andrade, B.F. (2007). Effects of methylphenidate and behavior modification on the social and academic behavior of children with disruptive behavior disorders: The moderating role of callous/unemotional traits. Journal of Clinical Child and Adolescent Psychology, 36, 629-644.

Wolke, D., Waylen, A., Samara, M., Steer, C., Goodman, R., Ford, T., et al. (2009). Selective drop-out in longitudinal studies and non-biased prediction of behaviour disorders. British Journal of Psychiatry, 195, 249-256.

Wooten, J.M., Frick, P.J., Shelton, K.K., \& Silverthorn, P. (1997). Ineffective parenting and childhood conduct problems: The moderating role of callous-unemotional traits. Journal of Consulting and Clinical Psychology, 65, 301308.

Accepted for publication: 17 January 2011

Published online: 16 March 2011 